\title{
Desenvolvimento e Estrutura Interna de uma Escala de Competências Gerenciais
}

\author{
Hugo Pena Brandão ${ }^{1}$ \\ Jairo Eduardo Borges-Andrade \\ Universidade de Brasilia \\ Isa Aparecida de Freitas \\ Universidade Corporativa Banco do Brasil \\ Fernanda Teles Vieira \\ Universidade de Brasilia
}

\begin{abstract}
RESUMO - Este estudo objetivou desenvolver uma escala para avaliar competências gerenciais. Buscou-se identificar competências relevantes ao desempenho de gestores de um banco, bem como verificar em que medida tais gestores expressam essas competências no trabalho. Os dados foram coletados por meio de levantamento documental, entrevistas e questionários estruturados. Estes foram respondidos por 331 gestores da organização estudada, sendo os dados submetidos a análises descritiva e fatorial. Os resultados revelaram 31 competências gerenciais, agrupadas em seis fatores denominados "estratégia e operações", "resultado econômico", "clientes", "comportamento organizacional", "processos internos" e "sociedade". Na autoavaliação, em geral, os participantes indicaram expressar razoavelmente tais competências no trabalho, a exceção daquelas associadas ao fator "sociedade", que parecem necessitar de aprimoramento.
\end{abstract}

Palavras-chave: competências gerenciais; desempenho no trabalho; escala de medida; análise fatorial.

\section{Development and Internal Structure of a Management Competencies Scale}

\begin{abstract}
This study aimed at developing a scale to evaluate management competencies. It was intended to identify competencies that would be relevant to the performance of bank managers, as well as to verify whether such managers express those competencies at work. The data were collected through documental search, interviews and structured questionnaires. The questionnaires were answered by 331 bank managers, and the data were submitted to descriptive and factorial analysis. Results revealed 31 management competencies, which were grouped into six factors named "strategy and operations", "economic output", "customers", "organizational behavior", "internal processes" and "society". In the participant's self-evaluation, in general, they indicated to reasonably express those competencies at work, except for those associated to the "society" factor, which seem to need improvement.
\end{abstract}

Keywords: management competencies; performance at work; scale of measurement; factorial analysis.

Com a emergência, na última década, de modelos de gestão baseados em competências (Barbosa \& Rodrigues, 2005; Brandão \& Guimarães, 2001; Dutra, 2004), grande discussão tem sido feita, tanto no meio acadêmico como no ambiente organizacional, em torno da noção de competência no trabalho, suas dimensões, implicações, antecedentes e consequentes (Le Boterf, 1999; Mclagan, 1997; Ruas, Ghedine, Dutra, Becker \& Dias, 2005).

As competências gerenciais constituem uma categoria que tem despertado crescente interesse por parte de teóricos, organizações e pesquisadores (Bitencourt, 2004; Santos, 2001; Spencer \& Spencer, 1993), talvez por causa da suposição de que elas exercem considerável influência sobre o desempenho de equipes de trabalho e, por conseguinte, sobre os resultados organizacionais. Apesar dos esforços que têm sido realizados, sobretudo no campo teórico, para explicar a natureza da competência gerencial, muitas questões permanecem sem resposta. Há carência de pesquisas destinadas

1 Endereço para correspondência: SCES Trecho 2, Lote 22, Ed. Presidente Tancredo Neves, $1^{\circ}$ andar. Brasília, DF. CEP 70.200-002. E-mail: hugopb@tba.com.br. a investigar antecedentes e consequentes da expressão de competências no trabalho (Brandão, 2007).

O presente estudo objetivou desenvolver uma escala de competências gerenciais. Procurou-se identificar e descrever competências relevantes ao desempenho de gestores de um banco público, bem como propor uma escala capaz de mensurar em que medida tais gestores expressam ${ }^{2}$ essas competências no trabalho.

Como a competência constitui um conceito em evidência, complexo e multifacetado (Brandão \& Borges-Andrade, 2007; Gonczi, 1999), espera-se que a construção de uma escala de medida de competências gerenciais possa facilitar a realização de investigações empíricas sobre o tema e o teste

2 Na presente pesquisa, optou-se por utilizar o termo "expressão de competências no trabalho" para referir-se a comportamentos adotados pelas pessoas em seu contexto produtivo, o que, conforme exposto adiante, constitui uma das facetas do desempenho individual. Para designar essa variável, preferiu-se não utilizar o termo "desempenho individual" porque este pode ser mensurado não apenas pela expressão de competências no trabalho, mas também pelos resultados decorrentes e pela comparação entre as pessoas, entre outros critérios de avaliação existentes (Brandão, 2007; Carbone, Brandão, Leite \& Vilhena, 2005). 
de certas suposições e construções teóricas, trazendo, assim, contribuições àqueles que desejam investigar a existência de relações entre a competência gerencial e outras variáveis do comportamento organizacional.

À organização estudada, em particular, os resultados do presente estudo podem ser úteis para orientar a realização de intervenções organizacionais nas áreas de recrutamento, seleção, treinamento, desenvolvimento e gestão do desempenho, por exemplo. Podem, ainda, oferecer contribuições aos gestores da empresa, posto que a identificação de competências relevantes ao desempenho desses gestores pode orientar processos de autodesenvolvimento e de gestão de suas carreiras.

\section{A Noção de Competência no Trabalho}

No início do século passado, o termo competência foi incorporado à linguagem organizacional, sendo usado fundamentalmente para qualificar a pessoa capaz de desempenhar com eficiência determinada função (Carbone \& cols., 2005). Nas últimas décadas, muitos autores procuraram criar definições próprias para o termo, chamando a atenção para variados aspectos da competência. Gilbert (1978), por exemplo, destacou que a competência seria expressa em função do comportamento da pessoa no trabalho, enquanto Durand (2000) deu ênfase a elementos que constituem a competência, ou seja, aos conhecimentos, habilidades e atitudes de que dispõe a pessoa.

Não obstante a possibilidade de interpretar a competência de múltiplas maneiras (McLagan, 1997; Ruas \& cols., 2005), é possível perceber a existência de duas grandes correntes teóricas, como sugere Dutra (2004). A primeira, representada principalmente por autores norte-americanos (e.g., Boyatzis, 1982; McClelland, 1973), apresenta a competência como um conjunto de qualificações ou características subjacentes à pessoa (como conhecimentos, habilidades e atitudes), que permitem a ela realizar um trabalho ou lidar com uma dada situação. A segunda, representada sobretudo por autores franceses (e.g., Le Boterf, 1999; Zarifian, 1999), associa a competência não a atributos ou qualificações da pessoa, mas sim às suas realizações em um dado contexto, ou seja, àquilo que o indivíduo produz ou realiza no trabalho.

Nos últimos anos, uma vertente integradora tem procurado definir a competência a partir da junção de concepções das referidas correntes. Esse posicionamento é defendido por Gonczi (1999), para quem a competência possui o caráter de associar atributos pessoais ao contexto em que são utilizados, isto é, ao ambiente e ao trabalho que a pessoa realiza. A competência é compreendida, então, não apenas como um conjunto de conhecimentos, habilidades e atitudes necessários para exercer certa atividade, mas também como comportamentos adotados pela pessoa no trabalho e realizações deles decorrentes (Carbone \& cols., 2005).

Sob essa ótica, competências podem ser entendidas como combinações sinérgicas de conhecimentos, habilidades e atitudes, expressas pelo desempenho dentro de um contexto organizacional, as quais agregam valor a pessoas e organizações (Freitas \& Brandão, 2006). Definições como essa possuem caráter integrador e multifacetado, na medida em que consideram as diversas dimensões (cognitiva, psicomotora e afetiva) do trabalho e associam a competência ao desempenho, no âmbito de uma estratégia ou de um contexto organizacional.

A aplicação de conhecimentos, habilidades e atitudes no trabalho, portanto, gera um desempenho profissional (Durand, 2000; Gonczi, 1999). Esse desempenho, por sua vez, é expresso pelos comportamentos que a pessoa manifesta e pelas consequências desses comportamentos, em termos de realizações ou resultados (Gilbert, 1978), de tal forma que o desempenho competente possui valor, seja ele econômico ou social, tanto para a pessoa que o produz quanto para a organização em que ela trabalha (Fleury \& Fleury, 2001).

Até aqui, referiu-se à competência no plano individual, como um atributo de uma pessoa. É possível, no entanto, elevar esse conceito a outros níveis. Muitos autores associam a noção de competência não apenas a pessoas, mas também a equipes de trabalho ou mesmo à organização por completo (Prahalad \& Hamel, 1990; Fleury \& Fleury, 2001). Zarifian (1999), por exemplo, sustenta que não se deve desconsiderar a dimensão da equipe no processo produtivo. Para ele, existiria um efeito de sinergia entre as competências individuais e as interações sociais estabelecidas no grupo. Da mesma forma, Le Boterf (1999) comenta que a competência de uma equipe constitui uma propriedade que emerge das relações sociais que se estabelecem no grupo e da articulação entre as competências individuais de seus integrantes.

Prahalad e Hamel (1990), por sua vez, elevam o conceito ao nível organizacional, referindo-se à competência como um atributo da organização, que a torna eficaz e permite a consecução de seus objetivos. Para esses autores, competências são atributos organizacionais que conferem vantagem competitiva, geram valor distintivo percebido pelos clientes e são difíceis de ser imitadas pela concorrência. Nessa mesma linha, Arrègle (1995) define a competência como o saber que a empresa acumulou ao longo de sua existência.

Tais proposições, segundo Brandão e Guimarães (2001), permitem classificar as competências como humanas ou individuais (aquelas relacionadas a profissionais, no plano individual) e organizacionais (aquelas que se referem a atributos ou capacidades da organização em sua totalidade ou de suas unidades produtivas). Um nível influencia o outro, de tal forma que as competências individuais afetam as competências organizacionais e ao mesmo tempo são influenciadas por estas.

Dependendo da abordagem teórica adotada ou da finalidade prática que se deseja atribuir ao conceito, existem outras tipologias e possibilidades de classificação das competências (Cockerill, 1994; Sparrow \& Bognanno, 1993). Em função da natureza do papel ocupacional desempenhado pelas pessoas, por exemplo, as competências individuais podem ser classificadas como técnicas ou gerenciais, como sugere Cockerill (1994). Nesse caso, as competências técnicas seriam aquelas relevantes a profissionais que desempenham atividades técnicas, de assessoramento ou operacionais, sem o exercício formal da liderança, enquanto as gerenciais - as quais constituem o foco da presente investigação - representariam comportamentos esperados daqueles que exercem funções de supervisão ou direção. Em geral, tais competências são descritas em termos de padrões comportamentais, 
que representam expectativas da organização em relação ao desempenho de seus empregados (Gonczi, 1999).

Nesse sentido, alguns pesquisadores e organizações têm procurado identificar competências importantes ao desempenho de gestores, visando sobretudo promover o seu desenvolvimento (MCI, 1997; Whiddett \& Hollyforde, 1999). Em estudo realizado no banco britânico National Westminster - NatWest, por exemplo, Cockerill (1994) utilizou entrevistas para identificar 11 competências gerenciais relevantes ao contexto em que atuava esse banco. Em seguida, por meio de questionários de auto e heteroavaliação, procurou mensurar em que medida gestores do NatWest manifestavam tais competências no trabalho. Verificou também que essas competências eram consistentes internamente e que estavam significativamente associadas a medidas de desempenho das unidades gerenciadas pelos participantes da pesquisa. Entre as competências identificadas, é possível mencionar a capacidade de o gestor "organizar equipes cooperativas nas quais os integrantes se sintam valorizados" e de "estabelecer planos e metas ambiciosos, visando maximizar resultados" (Cockerill, 1994, p. 73, tradução).

Spencer e Spencer (1993), baseando-se em tendências e pesquisas sobre o ambiente empresarial americano, elaboraram uma matriz de competências importantes para gerentes. Entre as várias competências gerenciais apontadas como relevantes por esses autores, é possível citar a capacidade de "disseminar a estratégia organizacional, fazendo despertar o envolvimento e o comprometimento dos empregados" e de "delegar tarefas e estimular os empregados a assumir maiores responsabilidades" (pp. 343-344, tradução livre).

Estudo realizado por Levenson, Van der Stede e Cohen (2006), por sua vez, procurou mensurar competências de gestores de uma empresa do setor industrial e examinar se estas influenciavam o desempenho (resultado obtido) dos gerentes e de suas unidades produtivas. A amostra foi constituída por 699 gestores, agrupados em 51 unidades da empresa. Empregando análise de regressão múltipla, esses autores verificaram que, no plano individual, as medidas de competências gerenciais, em conjunto com outras variáveis (anos de experiência, escolaridade do gestor e a participação dele em processos de mentoring), explicavam cerca de $11 \%$ ( $R^{2}$ ajustado) do desempenho do gestor (medido em termos de resultados obtidos). Encontraram também pequena relação positiva $\left(R^{2}\right.$ ajustado $\left.=0,05\right)$ entre os escores agregados de competências gerenciais (média em cada unidade) e o desempenho da unidade.

Há ainda pesquisas que se dedicam a investigar relações entre medidas de competências e outras variáveis do campo do comportamento organizacional. É o caso de Elliot, Faler, McGregor, Campbell, Sedikides e Harackiewicz (2000), que realizaram dois estudos com amostras independentes de pessoas em situações de trabalho simulado. Por meio de regressão múltipla, verificaram nos dois estudos que, quando submetidos a feedback positivo, os participantes reportam maiores níveis de competência percebida (grau com que o indivíduo avalia que desempenha bem uma atividade). Esta, por sua vez, revelou efeito significante sobre a motivação do indivíduo no trabalho.

A presente pesquisa está estruturada em dois estudos, que se sucedem e se complementam. O primeiro buscou identifi- car e descrever competências relevantes ao desempenho de gestores de um banco público. O segundo procurou mensurar em que medida tais gestores expressam essas competências no trabalho, bem como revelar fontes de evidências de validade da escala de medida dessas competências.

\section{Estudo 1}

\section{Método}

\section{Características da organização estudada}

Esta pesquisa foi realizada no Banco do Brasil, primeiro banco nacional, fundado em 1808. Sociedade de economia mista, estruturada sob a forma de conglomerado financeiro, a empresa tem como missão "ser a solução em serviços e intermediação financeira, atender às expectativas de clientes e acionistas, fortalecer o compromisso entre os funcionários e a Empresa e contribuir para o desenvolvimento do País" (Banco do Brasil, 2007). Quando esta pesquisa foi realizada, o Banco possuía 3.977 agências, 79.310 funcionários, 9.800 estagiários, R\$ 332 bilhões de ativos e 24 milhões de clientes correntistas (pessoas físicas e jurídicas) (Banco do Brasil, 2007).

As agências do Banco respondem pela distribuição dos produtos e serviços e estão segmentadas em quatro redes distintas de atendimento: varejo, atacado, governo e exterior. A Rede Varejo, objeto desta pesquisa, é a que possui maior quantidade de agências, funcionários, clientes e negócios. Cada agência é administrada por funcionário concursado, que exerce o cargo de Gerente Geral. Dependendo do seu porte, do potencial do mercado em que atua, do número de funcionários e de clientes, uma agência pode possuir outros níveis gerenciais (gerentes de segmento e de módulo).

Baseando-se nas premissas do modelo gerencial denominado Balanced Scorecard - BSC (Kaplan \& Norton, 1997), o Banco administra o desempenho de suas agências por meio do estabelecimento de objetivos e metas, alinhadas à estratégia organizacional, em seis diferentes perspectivas: estratégia e operações; resultado econômico; clientes; comportamento organizacional; processos internos; e sociedade (Banco do Brasil, 2005; Brandão \& cols., 2008).

A perspectiva Estratégia e Operações avalia o alinhamento das ações gerenciais às estratégias, planos de negócios e acordos de trabalho do Banco, focalizando a criação de valor no longo prazo, enquanto o Resultado Econômico agrega indicadores afetos à geração de resultados econômico-financeiros a partir dos recursos disponíveis, visando fortalecer a rentabilidade, a estrutura patrimonial e o valor da empresa. A perspectiva Clientes, por sua vez, concentra medidas referentes ao atendimento das expectativas dos clientes (externos e/ou internos) a partir de atributos valorizados por cada segmento do mercado, visando ampliar a base de clientes e sua satisfação. O Comportamento Organizacional avalia o grau de contribuição das unidades da empresa para o desenvolvimento profissional, a manutenção de um bom clima de trabalho e a melhoria da saúde ocupacional, buscan- 
do fortalecer a relação entre o Banco e seus funcionários. A perspectiva Processos Internos é composta por indicadores afetos à melhoria dos processos produtivos e de mecanismos de segurança e controle, visando obter maior confiabilidade e excelência no trabalho. A perspectiva Sociedade, por fim, está relacionada à promoção do desenvolvimento regional sustentável, à responsabilidade socioambiental e ao desenvolvimento econômico e social do País (Banco do Brasil, 2005; Brandão \& cols., 2008).

\section{Amostra}

Os dados foram coletados junto a 20 funcionários, entre gestores de agências e da direção do Banco, selecionados por critério de acessibilidade. Os participantes eram, em sua maioria, do sexo masculino $(60 \%)$, trabalhavam na rede de agências (85\%), possuíam idade superior a 40 anos $(85 \%)$, trabalhavam há mais de 15 anos na Empresa (80\%), tinham curso de pós-graduação lato ou stricto sensu (65\%) e estavam localizados em diferentes unidades da federação.

\section{Instrumentos}

Para coleta dos dados, foram utilizadas entrevistas pessoais, semi-estruturadas, individuais ou em duplas, com o propósito de obter descrições de situações profissionais, comportamentos observados no trabalho, papéis gerenciais e outros elementos que pudessem subsidiar a identificação de competências relevantes ao desempenho de gestores do Banco.

O presente estudo valeu-se também de levantamento documental, em bibliotecas e arquivos da organização estudada. Foram identificados relatórios, registros, normativos, bases de dados, fascículos formativos e estudos sobre formação de gestores e competências relevantes ao desempenho gerencial. Entre esses materiais, é possível destacar o catálogo de cursos da Universidade Corporativa Banco do Brasil - UniBB, o fascículo Referenciais de Gestão (Banco do Brasil, 2006) e os critérios e instrumentos utilizados para avaliação de desempenho dos gestores da empresa (Banco do Brasil, 2005).

\section{Procedimento}

As entrevistas foram realizadas em maio e junho de 2007, nas dependências da própria empresa, e tiveram duração média de 43 minutos cada. No início das entrevistas, foram expostos aos participantes o objetivo e a relevância da pesquisa, a importância de sua colaboração, bem como garantido que suas respostas seriam anônimas e que as informações prestadas não seriam utilizadas para outra finalidade. As perguntas foram efetuadas seguindo roteiro específico, tendo sido gravados os depoimentos e registradas notas que facilitaram o entendimento das respostas, conforme procedimentos sugeridos por Lodi (1991).

Seguindo as proposições de Richardson (1999), foram transcritas as respostas às questões da entrevista, depuradas as anotações realizadas e interpretadas as declarações dos entrevistados, destacando-se o significado atribuído a elas. Os dados foram tratados por meio de análise de conteúdo, procurando-se identificar elementos interpretativos e a frequência de uso de determinadas expressões, conforme sugerido por Wells (1991), visando descrever de forma objetiva e sistemática as competências gerenciais mencionadas pelos entrevistados como relevantes ao seu desempenho.

Tais competências foram cotejadas com aquelas descritas em documentos da organização estudada e em estudos anteriores (Bitencourt, 2004; Cockerill, 1994; Echeveste, Vieira, Viana, Trez \& Panosso, 1999; Kaplan \& Norton, 1997; Levenson \& cols., 2006; Maurik, 1997; MCI, 1997; Santos, 2001; Spencer \& Spencer, 1993; Stuart \& Lindsay, 1997). Foram identificadas ao todo 57 competências gerenciais, as quais foram descritas em termos de comportamentos observáveis. Procurou-se observar os procedimentos sugeridos por Brandão e Bahry (2005), Carbone e cols. (2005) e Mager (1990) para descrição operacional de competências, de forma que se buscou evitar a formulação de frases longas ou com múltiplas ideias e a utilização de expressões ambíguas, excessivamente técnicas, extremadas ou negativas. Essas competências foram então ordenadas, agrupadas por similaridade semântica e editadas, eliminando-se as que representavam duplicidades, abstrações ou irrelevâncias.

Desse procedimento, restaram 39 competências. Apurouse a frequência com que cada uma delas foi mencionada pelos entrevistados. Em seguida, o primeiro autor deste artigo classificou as competências nas seis perspectivas de avaliação - anteriormente descritas - do modelo de gestão de desempenho do Banco do Brasil. Essa categorização foi submetida à análise de cinco juízes (gestores e analistas do Banco que possuíam grande experiência e conhecimento sobre o modelo de gestão da empresa). Para que a classificação de cada competência fosse considerada válida, adotou-se como critério a necessidade de pelo menos quatro dos cinco juízes ter classificado a competência na mesma perspectiva de desempenho da categorização originalmente realizada. Apenas cinco não atenderam a esse critério. Essas competências tiveram, então, sua redação aprimorada e foram novamente submetidas à análise dos juízes, até que pelo menos quatro destes manifestassem consenso em relação à classificação. Uma das competências foi eliminada, posto que se revelou ambígua, sendo classificada pelos juízes em diferentes perspectivas de desempenho.

\section{Resultados e Discussão}

Foram identificadas 38 competências relevantes ao desempenho de gerentes de agências bancárias, distribuídas em seis categorias: estratégia e operações (5 itens), resultado econômico (5 itens), clientes ( 7 itens), comportamento organizacional ( 8 itens), processos internos ( 7 itens) e sociedade (6 itens). A Tabela 1 apresenta as competências identificadas, a frequência com que foram mencionadas pelos entrevistados, a indicação se a literatura revisada e a análise documental sugeriam a relevância delas, e a categoria a qual cada uma foi vinculada. 
Tabela 1. Competências identificadas como relevantes segundo a literatura, a análise documental e os entrevistados.

\section{Competências Gerenciais}

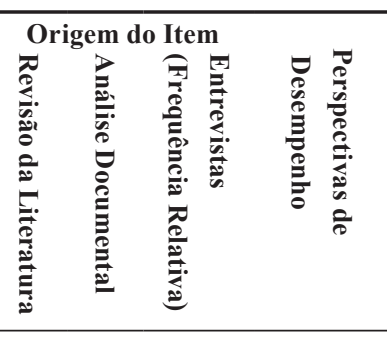

Comunica à sua equipe os indicadores e metas definidas no Acordo de Trabalho, informando claramente os rumos a serem seguidos pela agência.

Formula planos e estratégias para cumprir o Acordo de Trabalho, estabelecendo objetivos, ações, atribuições, prazos e prioridades.

Identifica forças, fraquezas, ameaças e oportunidades na área em que atua, visando estabelecer estratégias adequadas de atuação.

Monitora os indicadores de desempenho do Acordo de Trabalho, para alcançar as metas.

X $\quad 35 \%$

Aproveita as oportunidades que surgem para a agência, visando atingir metas nas diferentes perspectivas do Acordo de Trabalho.

Cobra dívidas inadimplidas, a fim de melhorar o resultado financeiro da agência.

Controla despesas administrativas, visando otimizar o resultado financeiro da agência.

Promove a realização de negócios que oferecem maior rentabilidade para a agência.

Racionaliza o uso de recursos (materiais, tecnológicos, financeiros etc) para que a agência possa obter maior lucratividade.

Analisa o desempenho de carteiras (de crédito ou de clientes, por exemplo), visando incrementar o volume e a rentabilidade dos negócios.

Presta atendimento de excelência ao cliente, procurando satisfazer às suas expectativas.

Gerencia o relacionamento com clientes, pautando-se no respeito, na cortesia e na ética.

Promove a venda de produtos e serviços a clientes, com transparência e confiabilidade.

Negocia com clientes de forma transparente, buscando estabelecer acordos satisfatórios para o Banco e para a clientela.

Presta consultoria ao cliente, ajudando-o na escolha do produto ou serviço que melhor atenda às suas necessidades. Identifica clientes em potencial, a fim de ampliar a base de clientes da agência.

Comunica-se com o cliente, adotando linguagem clara, objetiva e acessível.

Mobiliza os esforços dos funcionários em torno de propósitos comuns, estimulando o comprometimento deles com os objetivos e os resultados do Banco.

Orienta a atuação dos integrantes de sua equipe, comunicando claramente suas expectativas sobre o desempenho deles.

Estimula a participação dos funcionários na tomada de decisões, valorizando as contribuições oferecidas por eles.

Gerencia conflitos no trabalho, procurando manter a coesão e a harmonia entre funcionários.

Distribui adequadamente as tarefas entre os integrantes de sua equipe, de acordo com as capacidades e preferências de cada um.

Promove o desenvolvimento profissional dos integrantes de sua equipe, oferecendo a eles oportunidades de capacitação.

Colabora com os colegas de trabalho, a fim de concretizar os objetivos do Banco em um clima de harmonia.

Adota medidas preventivas e corretivas para melhoria da saúde, do bem-estar e da qualidade de vida dos integrantes de sua equipe.

Monitora a qualidade dos processos internos, para evitar o retrabalho.

Localiza rapidamente as informações de que necessita para o trabalho, consultando bases de dados, sistemas de informação e aplicativos do Banco.

Propõe soluções criativas para resolver problemas nos processos de trabalho.

Acompanha a conformidade dos processos sob sua responsabilidade, observando leis, normas e procedimentos estabelecidos.

Aprimora continuamente processos de trabalho, para otimizar a utilização dos recursos disponíveis (materiais, tecnológicos e humanos, por exemplo).

Organiza suas atividades e tarefas diárias para realizá-las no prazo previsto.

Implementa ações adequadas para reduzir o risco de atividades sob sua responsabilidade.

Toma decisões levando em consideração os possíveis impactos sobre o meio ambiente e a comunidade em que vive.

Promove ações que contribuem para o desenvolvimento sustentável da comunidade, demonstrando preocupação com as questões sociais.

Estimula a realização de trabalhos voluntários, visando contribuir para o desenvolvimento social e econômico da comunidade em que vive.

Estimula os integrantes de sua equipe a agirem de acordo com princípios de RSA do Banco.

Ao realizar operações de crédito, direciona a aplicação de recursos para empresas que possuem maior responsabilidade socioambiental.

Promove a economia de recursos naturais, adotando medidas para racionalizar o uso de papel, água e energia na agência.

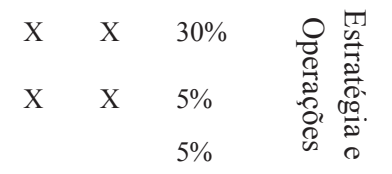

\begin{tabular}{|c|c|c|c|}
\hline X & $\mathrm{X}$ & & \\
\hline & $\mathrm{X}$ & $15 \%$ & \\
\hline & $\mathrm{X}$ & $15 \%$ & (T) \\
\hline & & $10 \%$ & § \\
\hline X & & $5 \%$ & 응 \\
\hline
\end{tabular}

\begin{tabular}{lll} 
& X \\
\hline X & X & $35 \%$ \\
& X & $30 \%$ \\
& & $30 \%$
\end{tabular}

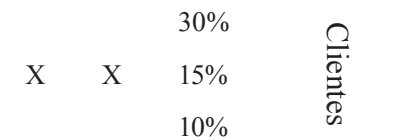

$10 \%$
$10 \%$

\begin{tabular}{|c|c|c|c|}
\hline X & X & $5 \%$ & \\
\hline X & X & $50 \%$ & $\Omega$ \\
\hline X & $X$ & $45 \%$ & 8 \\
\hline X & X & $25 \%$ & き \\
\hline X & & $15 \%$ & $\stackrel{\varrho}{\stackrel{2}{*}}$ \\
\hline X & & $15 \%$ & $\supseteqq$ \\
\hline X & $X$ & $10 \%$ & $\stackrel{\Xi}{\mathrm{E}}$. \\
\hline \multirow[t]{2}{*}{ X } & $X$ & & อె. \\
\hline & $X$ & & 0 \\
\hline
\end{tabular}

\begin{tabular}{|c|c|c|c|}
\hline X & \multirow{3}{*}{ X } & $55 \%$ & \multirow{7}{*}{ 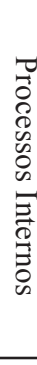 } \\
\hline X & & $55 \%$ & \\
\hline X & & $40 \%$ & \\
\hline X & X & $30 \%$ & \\
\hline X & X & $20 \%$ & \\
\hline \multirow[t]{2}{*}{ X } & $X$ & $10 \%$ & \\
\hline & X & $10 \%$ & \\
\hline & X & $25 \%$ & \multirow{5}{*}{$\begin{array}{l}\infty \\
0 \\
\stackrel{\Omega}{0} \\
\stackrel{0}{0} \\
\frac{0}{0}\end{array}$} \\
\hline & X & $25 \%$ & \\
\hline & X & $15 \%$ & \\
\hline & \multirow[t]{3}{*}{$X$} & $10 \%$ & \\
\hline & & $10 \%$ & \\
\hline & & $5 \%$ & \\
\hline
\end{tabular}


Boa parte das competências identificadas (mais de 35\%) foi mencionada por pelo menos $25 \%$ dos entrevistados. Em investigações dessa natureza, o número de menções realizadas a respeito de determinada competência pode ser considerado um indicativo da sua importância relativa (Richardson, 1999). Entre as competências mais citadas pelos entrevistados (frequência igual ou superior a 45\%), encontram-se "localiza rapidamente as informações de que necessita para o trabalho" e "monitora a qualidade dos processos internos, para evitar o retrabalho", bem como "mobiliza os esforços dos funcionários em torno de propósitos comuns" e "orienta a atuação dos integrantes de sua equipe". As duas primeiras estão vinculadas à perspectiva de desempenho "processos internos" (Brandão \& cols., 2008; Kaplan \& Norton, 1997) e representam competências relativas à gestão de processos. As duas últimas, por sua vez, pertencem à perspectiva que o Banco do Brasil (2005) denominou "comportamento organizacional" em seu modelo gerencial (Brandão \& cols., 2008), a qual concentra competências de gestão de pessoas.

De outro lado, entre as competências referidas com menor frequência pelos entrevistados, encontram-se as vinculadas à perspectiva "resultado econômico". Isso parece representar certa contradição: as competências afetas ao desempenho econômico - tipicamente valorizadas na atividade bancária (Banco do Brasil, 2007) - são justamente aquelas menos citadas nas entrevistas.

Algumas das competências foram mencionadas não apenas pelos entrevistados. Seu conteúdo foi identificado também na análise de documentos da organização e na revisão de estudos anteriores, conforme mostra a Tabela 1, o que representa outro indicativo de sua relevância. Outras, embora não tenham sido citadas pelos entrevistados, foram apontadas em documentos da organização como importantes ao desempenho gerencial, razão pela qual foram mantidas na referida tabela.

As competências identificadas como relevantes, portanto, contemplam não apenas a percepção dos entrevistados, mas também proposições oriundas da revisão de estudos anteriores (Bitencourt, 2004; Boak \& Coolican, 2001; Cockerill, 1994; Echeveste \& cols., 1999; Kaplan \& Norton, 1997; Levenson \& cols., 2006; Maurik, 1997; MCI, 1997; Santos, 2001; Spencer \& Spencer, 1993; Stuart \& Lindsay, 1997) e da própria organização estudada (Banco do Brasil, 2006, 2007).

Feita a identificação das competências relevantes ao desempenho de gestores de agências do Banco, procurou-se então mensurar em que medida tais gestores expressam essas competências em seu trabalho, bem como avaliar a qualidade psicométrica dessa escala de medida, o que constitui a finalidade do Estudo 2, descrito a seguir.

\section{Estudo 2}

\section{Método}

Este segundo estudo também foi realizado no Banco do Brasil, tendo sido utilizados a amostra, o instrumento e os procedimentos a seguir descritos.

\section{Amostra}

Os dados foram coletados junto a 331 gerentes de agências do Banco, em outubro de 2007. Os participantes eram, em sua maioria, do sexo masculino (71\%), exerciam principalmente os cargos de gerente geral $(30 \%)$ e gerente de módulo (64\%), tinham idade superior a 35 anos (72\%) e trabalhavam há mais de 10 anos na Empresa (64\%). Possuíam em média cerca de oito anos de experiência no exercício de funções gerencias, tinham curso de graduação (33\%) e pósgraduação lato ou stricto sensu (44\%) e estavam localizados em diferentes unidades da federação.

\section{Instrumento}

Com as 38 competências identificadas no estudo anterior, formatou-se um questionário estruturado para coleta de dados. A primeira parte do instrumento possuía uma apresentação, com informações sobre a pesquisa e o caráter confidencial das respostas, agradecimentos à colaboração do respondente e orientações para resposta. Em seguida, foram listadas as competências, em relação às quais os respondentes deveriam assinalar o grau com que as expressavam em seu trabalho. Para tanto, utilizou-se uma escala com âncoras de significados opostos em seus extremos (tipo Osgood), constituída de 10 pontos, variando de 1 (não expresso a competência) a 10 (expresso plenamente a competência). Havia também no questionário espaço destinado à coleta de dados biográficos dos respondentes, como, por exemplo, gênero, tempo de serviço no Banco, escolaridade e cargo exercido.

Seguindo as proposições de Pasquali (1998), o instrumento foi submetido à validação semântica, antes de sua aplicação, visando verificar se o enunciado, a escala e os itens eram inteligíveis aos respondentes. Nessa etapa, realizou-se a aplicação do questionário a uma pequena amostra de 12 gestores de agências do Banco, procurando-se identificar eventuais falhas ou incorreções, eliminar ambiguidades e itens sugestivos, a fim de assegurar a compreensão dos itens e da escala por parte da população a que se destinava o instrumento. Em decorrência de críticas e sugestões oferecidas pelos respondentes, foram realizados pequenos ajustes no enunciado e em quatro itens.

\section{Procedimento}

Os questionários foram aplicados coletivamente, durante a realização de cursos internos da Empresa, tendo sido distribuídos e recolhidos pelos instrutores, sem identificação dos respondentes. Os dados foram coletados por meio de cooperação voluntária dos participantes, sem qualquer desvantagem para eles e garantindo-lhes que as informações prestadas não seriam utilizadas para outra finalidade.

Para tabulação e análise dos dados, utilizou-se o aplicativo SPSS - Statistical Package for the Social Sciences. Foram analisadas inicialmente as estatísticas descritivas univariadas dos 38 itens, visando identificar eventuais erros de digitação. 
Não foi identificado nenhum valor fora da amplitude normal da escala de avaliação (1 a 10 pontos). As médias e desvios padrão revelaram-se plausíveis e os coeficientes de variação (desvio padrão dividido pela média) mostraram-se superiores a 0,001 . Verificou-se que quatro sujeitos possuíam mais de $10 \%$ de respostas ausentes, razão pela qual foram excluídos das análises posteriores. Outro sujeito também foi excluído, porque assinalou a mesma resposta para praticamente todos os itens. Todas as variáveis, por sua vez, revelaram possuir menos de $2 \%$ de dados ausentes.

Depois, foram examinados os requisitos necessários para proceder a análise fatorial. No que diz respeito ao tamanho necessário da amostra, utilizou-se o critério proposto por Tabachnick e Fidell (1989) e Pasquali (2005), ou seja, o de que deve haver pelo menos cinco respondentes para cada variável observada. Esse requisito foi cumprido, visto que a amostra, depois de excluídos os cinco casos relatados, totalizou 326 sujeitos, isto é, quase nove respondentes para cada item do questionário. Foram analisados também os índices de skewness e kurtosis das variáveis e realizados testes de normalidade (K-S e Shapiro-Wilk), os quais indicaram a ausência de distribuição normal em diversos itens, sendo mais comum a assimetria negativa. A ausência de normalidade, no entanto, não constitui um problema grave na análise fatorial (Pasquali, 2005), posto que essa técnica é razoavelmente robusta a violações desse pressuposto, principalmente em amostras com mais de 200 sujeitos (Hair, Anderson, Tatham $\&$ Black, 2005; Pasquali, 2006). Assim, optou-se por realizar os procedimentos subsequentes utilizando os dados originais, sem a sua transformação.

Procurou-se, em seguida, verificar a linearidade das relações entre as variáveis, extraindo-se gráficos de dispersão bivariada entre pares de itens e examinando a magnitude das correlações entre eles. Essa análise, em geral, indicou a presença de associação linear entre os itens verificados, dois a dois, tendo as relações entre pares apresentado intensidades bem variadas. Embora em alguns pares fosse alta a intensidade dessas correlações, nenhuma se mostrou próxima ou superior a 0,90 , o que indicou ausência de multicolinearidade (Pasquali, 2005), requisito que também foi atendido.

Visando identificar a existência de casos extremos multivariados, por sua vez, utilizou-se a distância de Mahalanobis. Apurou-se que 31 respondentes constituíam casos extremos multivariados, o que poderia produzir impacto substancial sobre a matriz de correlações, por diminuir ou ampliar a magnitude das associações entre variáveis (Neiva, Abbad \& Tróccoli, 2007). Em decorrência, as análises posteriores foram realizadas com e sem a presença desses casos na amostra, a fim de examinar o seu impacto. Embora os resultados produzidos fossem fundamentalmente os mesmos, em termos da estrutura fatorial que será exposta adiante, a manutenção dos casos extremos prejudicava as cargas fatoriais de alguns itens. Assim, optou-se por excluí-los, visto que a eliminação deles não prejudicaria substancialmente o tamanho da amostra, que com esse ajuste passou a totalizar 294 casos.

Com base nas respostas desses indivíduos aos 38 itens, extraiu-se a matriz das correlações entre as variáveis, para verificar se esta era fatorável. A inspeção visual da Matriz R indicou a existência de algumas correlações acima de 0,60 e de um bom percentual (cerca de 75\%) de correlações superiores a 0,30 , índices que sugeriram a fatorabilidade dos dados. A medida de adequação amostral KMO revelou-se igual a 0,94, índice considerado "maravilhoso" por Kaiser (citado por Pasquali, 2005), indicando uma ótima adequação dos dados à análise fatorial. Examinando a matriz de correlações anti-imagem, por sua vez, verificou-se que os quadrados das correlações múltiplas $\left(\mathrm{R}^{2}\right)$, em sua grande maioria, eram superiores a 0,90 , o que indicou suficiente relação entre as variáveis para se proceder uma análise fatorial. Além disso, o fato de o determinante da matriz de correlações ser igual a 0,00000000996 (quase zero) indicou, pelo menos, que seu posto era inferior ao número de variáveis, outro indicativo de fatorabilidade (Pasquali, 2005). Considerando esses indicadores, verificou-se, então, quantos fatores da Matriz R comportava, o que é descrito a seguir.

\section{Resultados}

Para determinar o número de fatores, utilizou-se a análise dos componentes principais (PC) e, como critérios, os autovalores iguais ou superiores a 1 , a plotagem dos eigenvalues (scree plot), o percentual da variância explicada por fator, a variância total explicada, a comparação entre os autovalores da matriz de correlações e autovalores gerados randomicamente (análise paralela), a matriz residual de correlações e sobretudo a existência de significado teórico ou semelhança semântica entre as variáveis agrupadas em um mesmo fator.

No que se refere ao critério K1 (Kaiser, citado por Pasquali, 2005), que sugere abandonar todos os fatores cujo autovalor seja inferior a 1 , verificou-se a possibilidade de extração de até sete fatores. Pelo critério de Harman (1967), por sua vez, que estabelece que cada fator tenha no mínimo $3 \%$ de variância explicada, poder-se-ia extrair até seis fatores. O scree plot, por sua vez, apresentou indícios da existência de dois fatores, enquanto a análise paralela de Horn (citado por Pasquali, 2005) sugeriu existirem três fatores. A extração de sete fatores não parecia razoável, pois os últimos permitiam incrementar pouco a variância total explicada. A extração de apenas dois fatores, por outro lado, implicaria em uma variância total explicada de $45,75 \%$, percentual razoavelmente inferior aos $63,30 \%$ que se obtinha com a extração de sete fatores.

Procurou-se, então, utilizando o método de fatoração dos eixos principais (Principal Axis Factoring - PAF), com rotação oblíqua (promax), explorar inicialmente a extração de três fatores. Com essa solução de três fatores obteve-se, pela matriz residual, $26 \%$ de resíduos grandes (com valores absolutos superiores a 0,05 ), percentual relativamente elevado, que sinalizou a existência de outros fatores a serem extraídos, conforme recomenda Pasquali (2005). Com a extração de seis fatores, por sua vez, o percentual de resíduos grandes $(11 \%)$ revelou-se bem menor, sugerindo que esse número de fatores seria suficiente. Além disso, essa estrutura permitia plena interpretação, visto que as variáveis se agruparam, por significado teórico e semelhança semântica, exatamente em torno das categorias hipotetizadas, que representavam as seis perspectivas de avaliação do modelo de gestão do Banco do 
Brasil: estratégia e operações; resultado econômico; clientes; comportamento organizacional; processos internos; e sociedade (Brandão \& cols., 2008).

Foram, então, extraídos seis fatores pelo método de fatoração dos eixos principais (Principal Axis Factoring - PAF), com rotação oblíqua (promax), uma vez que se verificou a existência de correlações entre eles. Os fatores extraídos explicavam 59,94\% da variância, percentual bastante razoável. A adequação (goodness-of-fit) da análise fatorial, por sua vez, foi verificada pelo exame da matriz de correlações residuais. Nessa matriz, foram identificados 81 (11\%) resíduos com valores absolutos maiores que 0,05 , sendo a maioria desses resíduos pouco superiores a esse valor. Como o percentual de resíduos grandes revelou-se relativamente pequeno, havia, portanto, pouca variância comum não explicada pelos seis fatores, o que sugere a adequação da solução fatorial. Com base nos resultados dispostos na Matriz Padrão, foram eliminados quatro itens que apresentavam baixas cargas fatoriais (muito próximas ou inferiores a 0,30); outros dois, porque não guardavam relação semântica com os fatores a que se associaram; e um outro, porque revelou-se híbrido, apresentando cargas fatoriais de magnitudes semelhantes (diferenças inferiores a 0,1) em dois fatores.

Em seguida, verificou-se se os fatores eram consistentes, seguindo as recomendações de Pasquali (2005). Para tanto, utilizou-se o Alpha de Cronbach ( $\alpha$ ), coeficiente que reflete o grau de covariância dos itens entre si, por ser esse coeficiente, segundo Pasquali (1998), o índice geralmente utilizado para estimação da fidedignidade das variáveis constantes de cada fator. Os resultados obtidos estão dispostos na Tabela 2, que apresenta a estrutura fatorial da escala.

Verificou-se, também, que os fatores não eram independentes entre si, uma vez que, como mostra a Tabela 3, há razoável correlação entre eles. Como todos os seis fatores relacionam-se entre si, tal ocorrência insinua serem eles fatores primários, ou seja, subfatores de um fator de segunda ordem. Em decorrência, esse fator de segunda ordem foi extraído e teve a sua consistência analisada, utilizando-se para tanto as 31 variáveis (dispostas na Tabela 2) integrantes dos fatores primários. Nessa nova extração, forçada em apenas um fator, foi utilizada a mesma matriz de correlações e o método de fatoração dos eixos principais $(P A F)$, seguindo-se as recomendações de Pasquali (2005). O fator de segunda ordem extraído apresentou itens com cargas fatoriais superiores a 0,40 , variância total explicada de $37 \%$ e alpha de 0,94 .

Procurou-se, por fim, extrair os escores fatoriais, calculando-se a média dos itens que compõem cada fator primário, conforme sugerido por Pasquali (2005). A Tabela 4 mostra as médias e desvios padrão dos seis fatores de primeira ordem.

\section{Discussão}

Pode-se observar que quatro fatores primários produziram alphas superiores a 0,85, índices que indicam ótima consistência interna. Outros dois obtiveram alphas de 0,74 e 0,77, que, embora estejam mais próximos do limite inferior de aceitabilidade (Hair \& cols., 2005), ainda representam boa consistência. Como o Alpha de Cronbach é indicativo da constância dos fatores, esses resultados sugerem ser provável que tais fatores apareçam também em outras pesquisas que se utilizem dessa escala, na mencionada organização.

Analisando o conteúdo dos itens que compõem cada fator primário, é possível observar, na Tabela 2, que o Fator 1 é constituído por competências relacionadas, por exemplo, à responsabilidade socioambiental e à contribuição do gestor para promover o desenvolvimento regional sustentável e a economia de recursos naturais. Tais variáveis possuem elevadas cargas fatoriais (iguais ou superiores a 0,60 ) e representam a Perspectiva Sociedade do modelo de gestão de desempenho da organização estudada (Banco do Brasil, 2005; Brandão \& cols., 2008). Essa perspectiva dá denominação simbólica ao fator, que revelou excelente consistência interna $(\alpha=0,88)$.

O Fator 2 também possui sete itens, com boas cargas fatoriais (superiores a 0,40$)$ e ótima consistência interna $(\alpha=$ $0,87)$. Eles descrevem competências referentes à Perspectiva Clientes, do modelo de gestão de desempenho do Banco do Brasil (Banco do Brasil, 2005; Brandão \& cols., 2008). Versam sobre qualidade, transparência, cortesia e confiabilidade no relacionamento com o cliente, bem como ampliação da base de clientes e de sua satisfação, entre outros aspectos, conforme disposto na Tabela 2 .

O Fator 3 também apresentou ótima consistência interna $(\alpha=0,86)$ e descreve competências relativas à Perspectiva Comportamento Organizacional, sua designação simbólica. Seus seis itens possuem boas cargas fatoriais (superiores a 0,40). Essa perspectiva do modelo de gestão da Empresa (Banco do Brasil, 2005; Brandão \& cols., 2008) refere-se ao grau de contribuição do gestor para a capacitação profissional dos integrantes de sua equipe e para a manutenção de um bom clima de trabalho, procurando fortalecer a relação entre o Banco e seus funcionários.

Os cinco itens integrantes do Fator 4 versam sobre a Perspectiva Estratégia e Operações. Abordam competências relacionadas ao alinhamento das ações gerenciais às estratégias, políticas, planos de negócios e acordos de trabalho da organização. Esse fator também revelou ótima consistência interna $(\alpha=0,87)$ e boas cargas fatoriais, conforme pode ser visto na Tabela 2.

Os dois últimos fatores ( 5 e 6 ) abrangem competências relativas, respectivamente, às perspectivas Processos Internos $(\alpha=0,74)$ e Resultado Econômico $(\alpha=0,77)$ do modelo de gestão de desempenho da Empresa (Banco do Brasil, 2005). Seus itens possuem ótimas ou boas cargas fatoriais. As consistências internas, embora estejam mais próximas do limite inferior de aceitabilidade (Hair \& cols., 2005), ainda são boas. A perspectiva Processos Internos agrega indicadores afetos à melhoria dos processos produtivos e de mecanismos de controle, visando obter maior confiabilidade e excelência no trabalho, enquanto a perspectiva Resultado Econômico refere-se à geração de resultados econômico-financeiros a partir dos recursos disponíveis, visando fortalecer a rentabilidade, a estrutura patrimonial e o valor da Empresa.

Os itens que integram cada fator primário possuem razoável semelhança semântica entre si. Como era esperado, seus significados teóricos refletem muito bem as seis dimensões do modelo de gestão de desempenho da organização estudada 
Tabela 2. Estrutura fatorial da Escala de Competências Gerenciais.

\begin{tabular}{|c|c|c|c|c|c|c|c|}
\hline Variáveis & F1 & F2 & F3 & F4 & F5 & F6 & $\mathbf{h}^{2}$ \\
\hline $\begin{array}{l}\text { C15 - Promove ações que contribuem para o desenvolvimento sustentável da comunidade, } \\
\text { demonstrando preocupação com as questões sociais. }\end{array}$ & 0,84 & & & & & & 0,64 \\
\hline $\begin{array}{l}\text { C26 - Estimula os integrantes de sua equipe a realizarem trabalhos voluntários, visando } \\
\text { contribuir para o desenvolvimento social e econômico da comunidade em que vive. }\end{array}$ & 0,81 & & & & & & 0,58 \\
\hline $\begin{array}{l}\text { C31 - Estimula os integrantes de sua equipe a agirem de acordo com os princípios de } \\
\text { responsabilidade socioambiental do Banco. }\end{array}$ & 0,79 & & & & & & 0,57 \\
\hline $\begin{array}{l}\mathrm{C} 12 \text { - Toma decisões no trabalho levando em consideração os possíveis impactos sobre o } \\
\text { meio ambiente e a comunidade em que vive. }\end{array}$ & 0,74 & & & & & & 0,58 \\
\hline $\begin{array}{l}\text { C16 - Ao realizar operações de crédito, direciona a aplicação de recursos para empresas } \\
\text { que possuem maior responsabilidade socioambiental. }\end{array}$ & 0,68 & & & & & 0,30 & 0,56 \\
\hline $\begin{array}{l}\text { C32 - Promove a economia de recursos naturais, adotando medidas para racionalizar o } \\
\text { uso de papel, água e energia na agência. }\end{array}$ & 0,66 & 0,34 & & & & & 0,55 \\
\hline $\begin{array}{l}\text { C11 - Adota medidas preventivas e corretivas para melhoria da saúde, do bem-estar e da } \\
\text { qualidade de vida dos integrantes de sua equipe. }\end{array}$ & 0,60 & & & & & & 0,59 \\
\hline C33 - Comunica-se com o cliente, adotando linguagem clara, objetiva e acessível. & & 0,75 & & & & & 0,63 \\
\hline $\begin{array}{l}\text { C29 - Negocia com clientes de forma transparente, buscando estabelecer acordos satisfa- } \\
\text { tórios para o Banco e para a clientela. }\end{array}$ & & 0,61 & & & & & 0,64 \\
\hline $\begin{array}{l}\text { C37 - Presta consultoria ao cliente, ajudando-o na escolha do produto ou serviço que } \\
\text { melhor atenda às suas necessidades. }\end{array}$ & & 0,57 & & & & & 0,56 \\
\hline $\begin{array}{l}\text { C25 - Promove a venda de produtos e serviços a clientes, com transparência e confiabili- } \\
\text { dade. }\end{array}$ & & 0,54 & & & & & 0,58 \\
\hline C34 - Identifica clientes em potencial, a fim de ampliar a base de clientes da agência. & & 0,53 & & 0,35 & & & 0,55 \\
\hline $\begin{array}{l}\text { C24 - Gerencia o relacionamento com clientes, pautando o atendimento no respeito, na } \\
\text { cortesia e na ética. }\end{array}$ & & 0,52 & 0,31 & & & & 0,60 \\
\hline $\begin{array}{l}\text { C21 - Presta atendimento de excelência ao cliente, procurando satisfazer às suas expecta- } \\
\text { tivas. }\end{array}$ & & 0,41 & & & & & 0,53 \\
\hline $\begin{array}{l}\text { C20 - Distribui adequadamente as tarefas entre os integrantes de sua equipe, de acordo } \\
\text { com as capacidades e aptidões de cada um. }\end{array}$ & & & 0,76 & & & & 0,59 \\
\hline $\begin{array}{l}\text { C28 - Mobiliza os esforços dos funcionários em torno de propósitos comuns, estimulando } \\
\text { o comprometimento deles com os objetivos e os resultados do Banco. }\end{array}$ & & & 0,73 & & & & 0,70 \\
\hline $\begin{array}{l}\text { C27 - Colabora com os colegas de trabalho, a fim de concretizar os objetivos do Banco em } \\
\text { um clima de harmonia. }\end{array}$ & & & 0,70 & & & & 0,54 \\
\hline $\begin{array}{l}\text { C5 - Gerencia conflitos no ambiente de trabalho, procurando manter a coesão e a harmo- } \\
\text { nia entre os funcionários. }\end{array}$ & & & 0,58 & & & & 0,53 \\
\hline $\begin{array}{l}\text { C38 - Orienta a atuação dos integrantes de sua equipe, comunicando claramente suas } \\
\text { expectativas sobre o desempenho deles. }\end{array}$ & & & 0,56 & 0,35 & & & 0,67 \\
\hline $\begin{array}{l}\text { C3 - Estimula a participação dos funcionários na tomada de decisões, valorizando as } \\
\text { contribuições oferecidas por eles. }\end{array}$ & & & 0,41 & & & & 0,56 \\
\hline $\begin{array}{l}\mathrm{C} 2 \text { - Comunica à sua equipe os indicadores e metas definidos no Acordo de Trabalho, } \\
\text { informando claramente os rumos a serem seguidos pela agência. }\end{array}$ & & & & 0,85 & & & 0,67 \\
\hline $\begin{array}{l}\mathrm{C} 1 \text { - Formula planos e estratégias para cumprir o Acordo de Trabalho, estabelecendo } \\
\text { objetivos, ações, atribuições, prazos e prioridades. }\end{array}$ & & & & 0,73 & & & 0,60 \\
\hline $\begin{array}{l}\text { C6 - Monitora os indicadores de desempenho do Acordo de Trabalho, para alcançar metas } \\
\text { estabelecidas. }\end{array}$ & & & & 0,70 & & & 0,65 \\
\hline $\begin{array}{l}\text { C7 - Identifica forças, fraquezas, ameaças e oportunidades na área em que atua, visando } \\
\text { estabelecer estratégias adequadas de atuação }\end{array}$ & & & & 0,43 & 0,31 & & 0,57 \\
\hline $\begin{array}{l}\text { C10 - Aproveita as oportunidades que surgem para a agência, visando atingir metas nas } \\
\text { diferentes perspectivas do Acordo de Trabalho. }\end{array}$ & & & & 0,36 & & & 0,58 \\
\hline C4 - Monitora a qualidade dos processos internos, para evitar o retrabalho. & & & & & 0,70 & & 0,50 \\
\hline C9 - Organiza suas atividades e tarefas diárias, para realizá-las no prazo previsto. & & & & & 0,70 & & 0,46 \\
\hline $\begin{array}{l}\text { C8 - Aprimora continuamente processos de trabalho, para aproveitar da melhor forma } \\
\text { possível os recursos disponíveis. }\end{array}$ & & & & & 0,51 & & 0,53 \\
\hline C17 - Promove a realização de negócios que oferecem maior rentabilidade para a agência. & & & & & & 0,59 & 0,59 \\
\hline $\begin{array}{l}\text { C18 - Analisa o desempenho de carteiras (de crédito ou de clientes, por exemplo), visando } \\
\text { incrementar o volume e a rentabilidade dos negócios. }\end{array}$ & & 0,32 & & & & 0,54 & 0,63 \\
\hline C13 - Cobra dívidas inadimplidas, a fim de melhorar o resultado financeiro da agência. & & & & & & 0,42 & 0,48 \\
\hline Autovalor & 14,52 & 2,87 & 1,83 & 1,36 & 1,22 & 1,16 & \\
\hline \% Variância Explicada & 38,20 & 7,55 & 4,81 & 3,59 & 3,20 & 3,05 & \\
\hline Número de Itens & 7 & 7 & 6 & 5 & 3 & 3 & \\
\hline Alpha de Cronbach & 0,88 & 0,87 & 0,86 & 0,87 & 0,74 & 0,77 & \\
\hline
\end{tabular}


Tabela 3. Matriz de correlações entre os seis fatores primários (correlações significantes ao nível de 0,05).

\begin{tabular}{lllllll}
\hline & Fator 1 & Fator 2 & Fator 3 & Fator 4 & Fator 5 & Fator 6 \\
\hline Fator 1 & 1 & & & & & \\
Fator 2 & 0,40 & 1 & & & & \\
Fator 3 & 0,53 & 0,69 & 1 & 1 & & \\
Fator 4 & 0,54 & 0,64 & 0,66 & 0,51 & 1 & 1 \\
Fator 5 & 0,40 & 0,50 & 0,56 & 0,64 & 0,43 & \\
Fator 6 & 0,39 & 0,68 & 0,51 & & & \\
\hline
\end{tabular}

(Banco do Brasil, 2005; Brandão \& cols., 2008), as quais se baseiam nas perspectivas do modelo gerencial denominado Balanced Scorecard (Kaplan \& Norton, 1997).

Nos fatores extraídos, as cargas fatoriais de seus itens podem ser consideradas fontes de evidência de validade. Os fatores revelaram-se consistentes internamente, visto que apresentaram alphas iguais ou superiores a 0,74 , indicando, de forma geral, bons índices de fidedignidade das variáveis integrantes de cada fator. Em estudos posteriores, poder-se-ia utilizar, portanto, apenas os escores fatoriais para cada respondente (nos seis fatores primários) e não mais os escores nos itens da escala. Como tais fatores primários relacionam-se entre si, constituem subfatores de um fator de segunda ordem, que igualmente revelou boa consistência interna e itens com boas cargas fatoriais, as quais representam fontes de evidência de sua validade. $\mathrm{O}$ escore fatorial desse unifator também poderia ser utilizado em investigações posteriores, representando o construto

Tabela 4. Escores fatoriais.

\begin{tabular}{lll}
\hline Fatores Extraídos & Média & $\begin{array}{l}\text { Desvio } \\
\text { Padrão }\end{array}$ \\
\hline Fator 1: Sociedade & 6,77 & 1,50 \\
Fator 2: Clientes & 8,75 & 0,77 \\
Fator 3: Comportamento Organizacional & 8,36 & 0,92 \\
Fator 4: Estratégia e Operações & 8,01 & 1,15 \\
Fator 5: Processos Internos & 7,95 & 1,01 \\
Fator 6: Resultado Econômico & 8,09 & 1,23 \\
\hline
\end{tabular}

competência gerencial, embora o uso dos seis fatores primários permita explorar melhor os principais componentes desse construto.

A maior média e o menor desvio padrão recaíram sobre o Fator 2 (Clientes), indicando que, na autoavaliação realizada pelos gestores de agências do Banco, houve homogeneidade e estes expressam quase plenamente, em seu desempenho, as competências relacionadas ao atendimento de necessidades e expectativas dos clientes, visando ampliar a base de clientes e sua satisfação. Em seguida, com média e desvio padrão de magnitudes semelhantes, está o fator Comportamento Organizacional. O Fator Sociedade, por outro lado, obteve a menor média e o maior desvio padrão, o que sugere maior heterogeneidade entre os participantes e a necessidade de muitos deles aprimorarem competências relacionadas à promoção do desenvolvimento regional sustentável, da responsabilidade socioambiental e do desenvolvimento econômico e social do País, ou de a organização oferecer maior apoio para tanto. Talvez esse resultado tenha se revelado justamente porque a perspectiva Sociedade foi apenas recentemente introduzida pelo Banco em seu modelo de gestão do desempenho (Banco do Brasil, 2005). Talvez uma boa parte dos gestores ainda não tenha desenvolvido plenamente as competências associadas a essa dimensão do seu desempenho.

\section{Considerações Finais}

O presente estudo permitiu identificar competências relevantes ao desempenho de gestores de agências bancárias. Foi realizada uma análise fatorial exploratória, procurandose revelar padrões de correlação entre essas competências e verificar a existência de dimensões subjacentes a elas.

Pela análise realizada, a solução com a extração de seis fatores primários revelou-se a mais adequada, ponderandose principalmente os autovalores iguais ou superiores a 1 , a variância total explicada, a matriz residual de correlações e a existência de significado teórico ou semelhança semântica entre as competências agrupadas em um mesmo fator. Os significados teóricos dos seis fatores extraídos refletem muito bem as dimensões do modelo de gestão de desempenho da organização estudada.

O método utilizado para realizar a presente investigação impõe algumas limitações a seus resultados. A utilização de amostra não-probabilística, por exemplo, pode ter subestimado a variedade dos componentes da população, trazendo limitações quanto à representatividade dos dados. A circunscrição da amostra a apenas uma organização, por sua vez, restringe os resultados à empresa estudada, impedindo sua generalização a outros contextos organizacionais. Além disso, não há garantia absoluta de que os julgamentos realizados pelos participantes representem indicadores confiáveis da expressão de competências no trabalho, pois estimativas baseadas em autorrelato podem conter imprecisões, erros de halo e outros vieses. Acredita-se que essas limitações potenciais, embora possam restringir os resultados, não invalidam a presente investigação, até porque esta possui caráter exploratório.

Os resultados apresentados evidenciaram indicadores psicométricos confiáveis, de forma que a escala de medida desenvolvida pode ser utilizada, com razoável segurança, tanto para conduzir investigações empíricas, quanto para orientar intervenções organizacionais, em especial no que se refere à gestão do desempenho gerencial e à identificação de necessidades de desenvolvimento de competências.

Considerando a relativa escassez de investigações empíricas sobre competências gerenciais, em especial no Brasil 
(Brandão, 2007), espera-se que os resultados apresentados neste estudo, sobretudo as fontes de evidência de validade apontadas para escala elaborada, possam ensejar a realização de novas pesquisas sobre o tema. Utilizando a escala aqui apresentada, organizações e pesquisadores poderiam se dedicar a, por exemplo:

a) Verificar se a estrutura fatorial da referida escala de competências revela-se também em estudos conduzidos em outras organizações, não só da indústria bancária, mas também de outros segmentos de negócios;

b) Comparar escores obtidos por meio de autoavaliação com escores oriundos de heteroavaliação;

c) Identificar características pessoais (como experiência, motivação, estratégias de aprendizagem no trabalho e domínio de conhecimentos, habilidades e atitudes) que influenciam a expressão de competências gerenciais no trabalho;

d) Examinar em que medida propriedades de equipes (como o clima organizacional) influenciam a expressão das competências gerenciais;

e) Identificar que características organizacionais (como oferta de treinamento, cultura, normas e valores, por exemplo) afetam a competência de indivíduos;

f) Verificar em que medida as competências expressas por gestores influenciam o desempenho organizacional; e

g) Identificar consequências da expressão de competências no trabalho, tanto para o empregado que as expressa quanto para a organização em que ele atua.

Tratando-se de estudo sobre um conceito em evidência e cujos pressupostos ainda carecem de investigações empíricas, espera-se que este artigo tenha oferecido contribuições teóricas e metodológicas ao estudo da competência no trabalho e nas organizações. Que ele indique caminhos e enseje a realização de pesquisas.

\section{Referências}

Arrègle, J. L. (1995). Le savoir et l'approche "Resource Based": Une ressource et une compétence. Revue Française de Gestion, 105, 84-94.

Banco do Brasil (2005). Gestão de desempenho por competências: integrando desenvolvimento profissional, desempenho e participação [Fascículo]. Programa Profissionalização, 31, 1-23.

Banco do Brasil (2006). Universidade Corporativa Banco do Brasil. Retirado em 29/12/2006, de http://uni.bb.com.br.

Banco do Brasil (2007). Retrato da empresa. Retirado em 02/12/2007, de http://www.bb.com.br.

Barbosa, A. C. Q., \& Rodrigues, M. A. (2005). Um olhar sobre os modelos de gestão de competências adotados por grandes empresas brasileiras [Resumo]. Em Associação Nacional dos Programas de Pós-Graduação em Administração (Org.), XXIX ENANPAD (p. 439). Brasília: ANPAD.

Bitencourt, C. C. (2004). A gestão de competências gerenciais e a contribuição da aprendizagem organizacional. Revista de Administração de Empresas, 44, 58-69.
Boak, G., \& Coolican, D. (2001). Competencies for retail leadership: Accurate, acceptable, affordable. Leadership and Organization Development Journal, 22, 212-220.

Boyatzis, R. E. (1982). The competent management: A model for effective performance. New York: John Wiley.

Brandão, H. P. (2007). Competências no trabalho: uma análise da produção científica brasileira. Revista Estudos de Psicologia, Natal (RN), 12, 149-158.

Brandão, H. P., \& Bahry, C. P. (2005). Gestão por competências: métodos e técnicas para mapeamento de competências. Revista do Serviço Público, 56, 179-194.

Brandão, H. P., \& Borges-Andrade, J. E. (2007). Causas e efeitos da expressão de competências no trabalho: para entender melhor a noção de competência. Revista de Administração Mackenzie, 8 , 32-49.

Brandão, H. P., \& Guimarães, T. A. (2001). Gestão de competências e gestão de desempenho: tecnologias distintas ou instrumentos de um mesmo constructo? Revista de Administração de Empresas, 41, 08-15.

Brandão, H. P., Zimmer, M. V., Guarçoni, C. P., Marques, F., Viana. H., Carbone, P. P., \& Almada, V. F. (2008). Gestão de desempenho por competências: integrando a gestão por competências, o balanced scorecard e a avaliação 360 graus. Revista de Administração Pública - RAP, 42, 875-898.

Carbone, P. P., Brandão, H. P., Leite, J. B., \& Vilhena, R. M. (2005). Gestão por competências e gestão do conhecimento. Rio de Janeiro: FGV.

Cockerill, T. (1994). The king of competence for rapid change. Em C. Mabey \& P. Iles (Orgs.), Managing learning (pp. 70-76). London: Routledge.

Durand, T. (2000). L'alchimie de la compétence. Revue Française de Gestion, 127, 84-102.

Dutra, J. S. (2004). Competências: conceitos e instrumentos para a gestão de pessoas na empresa moderna. São Paulo: Atlas.

Echeveste, S., Vieira, B., Viana, D., Trez, G., \& Panosso, C. (1999). Perfil do executivo no mercado globalizado. Revista de Administração Contemporânea, 3, 167-186.

Elliot, A. J., Faler, J., McGregor, H.A., Campbell, W. K., Sedikides, C., \& Harackiewicz, J. M. (2000). Competence valuation as a strategic intrinsic motivation process. Personality and Social Psychology Bulletin, 26, 780-794.

Fleury, A., \& Fleury, M. T. (2001). Estratégias empresariais e formação de competências. São Paulo: Atlas.

Freitas, I. A., \& Brandão, H. P. (2006). Trilhas de aprendizagem como estratégia de TD\&E. Em J. E. Borges-Andrade, G. Abbad \& L. Mourão (Orgs.), Treinamento, desenvolvimento e educação em organizações e trabalho: fundamentos para a gestão de pessoas (pp. 97-113). Porto Alegre: Artmed/Bookman.

Gilbert, T. (1978). Human competence: Engineering worthy performance. New York: McGraw-Hill Book.

Gonczi, A. (1999). Competency-based learning: A dubious past - an assured future? Em D. Boud \& J. Garrick (Orgs.), Understanding learning at work (pp. 180-194). London: Routledge.

Hair Jr., J. F., Anderson, R. E., Tatham, R. L., \& Black, W. C. (2005). Análise multivariada de dados. Porto Alegre: Bookman.

Harman, H. H. (1967). Modern factor analysis. Chicago: University of Chicago Press. 
Kaplan, R., \& Norton, D. P. (1997). A estratégia em ação: balanced scorecard. Rio de Janeiro: Campus.

Le Boterf, G. (1999). Competénce et navigation professionnelle. Paris: Éditions d'Organisation.

Levenson, A. R., Van der Stede, W. A., \& Cohen, S. G. (2006). Measuring the relationship between managerial competencies and performance. Journal of Management, 32, 360-380.

Lodi, J. B. (1991). A entrevista: teoria e prática. São Paulo: Pioneira.

Mager, R. F. (1990). Preparing instructional objectives: A critical tool in the development of effective instruction. Belmont: Fearon-Pitman.

Maurik, J. V. (1997). Beyond management competences: Pointers for future leadership development. Leadership and Organization Development Journal, 18, 312-316.

McClelland, D. (1973). Testing for competence rather than intelligence. American Psychologist, 28, 01-14.

MCI - Management Charter Initiative (1997). Management standars. London: Autor.

McLagan, P. A. (1997). Competencies: The next generation. Training \& Development, 51, 40-47.

Neiva, E. R., Abbad, G., \& Tróccoli, B. T. (2007). Roteiro para análise fatorial de dados [Manuscrito não publicado]. Instituto de Psicologia, Universidade de Brasília, Brasília.

Pasquali, L. (1998). Psicometria: teoria e aplicações. Brasília: UnB.

Pasquali, L. (2005). Análise fatorial para pesquisadores. Brasília: LabPAM.

Pasquali, L. (2006). Delineamento de pesquisa em ciência: fundamentos estatísticos da pesquisa cientifica. Brasília: LapPAM.

Prahalad, C. K., \& Hamel, G. (1990). The core competence of the corporation. Harvard Business Review, 68, 79-93.

Richardson, R. (1999). Pesquisa social: métodos e técnicas. São Paulo: Atlas.
Ruas, R., Ghedine, T., Dutra, J. S., Becker, G. V., \& Dias, G. B. (2005). O conceito de competência de A a Z: análise e revisão nas principais publicações nacionais entre 2000 e 2004 [Resumo]. Em Associação Nacional dos Programas de Pós-Graduação em Administração (Org.), XXIX ENANPAD (p. 459). Brasília: ANPAD.

Santos, A. C. (2001). O uso do método Delphi na criação de um modelo de competências. Revista de Administração da USP, $36,25-32$.

Sparrow, P., \& Bognanno, M. (1993). Competency requirement forecasting: Issues for international selection and assessment. International Journal of Selection and Assessment, 1, 50-58.

Spencer, L. M., \& Spencer, S. M. (1993). Competence at work: Models for superior performance. New York: John Wiley \& Sons.

Stuart, R., \& Lindsay, P. L. (1997). Beyond the frame of management competencies: Towards a contextually embedded framework of managerial competence in organizations. Journal of European Industrial Training, 21, 26-33.

Tabachnick, B., \& Fidell, L. S. (1989). Using multivariate statistics. New York: Harper Collins.

Wells, S. (1991). The role of analysis in qualitative research. Journal of the Market Research Society, 33, 39-44.

Whiddett, S., \& Hollyforde, S. (1999). The competencies handbook. London: Institute of Personnel and Development.

Zarifian, P. (1999). Objectif compétence: pour une nouvelle logique. Paris: Editions Liaisons. 